\title{
Experimental Study of Aerodynamic Damping of Typical Tall Buildings
}

\author{
Peng Huang, Yong Quan, and Ming Gu \\ State Key Laboratory of Disaster Reduction in Civil Engineering, Tongji University, Shanghai 200092, China \\ Correspondence should be addressed to Ming Gu; minggu@tongji.edu.cn
}

Received 19 August 2013; Accepted 24 September 2013

Academic Editor: Ting-Hua Yi

Copyright (C) 2013 Peng Huang et al. This is an open access article distributed under the Creative Commons Attribution License, which permits unrestricted use, distribution, and reproduction in any medium, provided the original work is properly cited.

\begin{abstract}
Aerodynamic damping in certain conditions appears to have a negative value, which increases the dynamic response of a tall building. Six single-degree-of-freedom (SDOF) aeroelastic models of tall buildings with typical cross sections (square, square with concave or bevel corners, and rectangular) are tested in a wind tunnel with a suburban terrain flow field condition. The along-wind and across-wind aerodynamic damping ratios of the tall buildings are identified by using the eigensystem realization algorithm (ERA) method in conjunction with the random decrement technique (RDT). The effects of wind speed, corner modifications (concave or bevel corner), side ratio, and wind direction on the aerodynamic damping are studied. The results indicate that in most cases the along-wind aerodynamic damping is positive and gradually increases with the increase of reduced wind speed $\left(U_{r}\right)$. The across-wind aerodynamic damping is likewise a positive value at low $U_{r}$ in most cases, but suddenly becomes negative when $U_{r}$ becomes greater than 10.5 for the square cross-section building.
\end{abstract}

\section{Introduction}

With the application of new materials and advanced technologies, modern tall buildings are becoming lighter and more slender than their predecessors, and thereby more sensitive to wind excitation. Aerodynamic damping may play an important role in estimating the dynamic response, especially in the wind excited across-wind dynamic response of tall buildings. Aerodynamic damping appears to have a negative value in certain conditions, which increases the dynamic response of the building.

Davenport [1], Holmes [2, 3], and Gabbai and Simiu [4] proposed a few methods to calculate the aerodynamic damping of high-rise structures for specific cases based on the quasi-steady assumption. The aerodynamic damping of tall buildings were mainly identified through wind tunnel tests because the along-wind and across-wind vibrations of tall buildings are highly complicated in the turbulent flow field, and the drastic change of the aerodynamic damping occurs at a high reduced velocity.

Kareem [5] pointed out that the effect of aerodynamic damping on the wind-induced vibration of high-rise buildings is not always negligible. He compared the responses of the buildings that were calculated in terms of the pressure distributions obtained from the wind tunnel tests of their rigid models with those from aeroelastic model tests. The across-wind aerodynamic damping of buildings appeared to have a negative value sometimes, which significantly increases the vibration amplitude of the building.

A number of studies on aerodynamic damping were then performed. Most of the researchers focused on the aerodynamic damping of square cross-section buildings [611]. Watanabe et al. [9] proposed an empirical aerodynamic damping function for tall buildings and prisms, including the effects of the tip amplitude, aspect ratio, shapes of crosssection, and turbulence intensity of the flow field. Quan et al. [11] studied the effects of the reduced wind velocity, terrain type, and structural damping ratio on the aerodynamic damping, which allowed the researchers to derive the formulas of across-wind and along-wind aerodynamic damping ratios of the square super high-rise building.

The cross-section shape highly impacts the aerodynamic damping of tall buildings. As such, Hayashida et al. [12], Marukawa et al. [8], Cheng and Chiang [10], and as some other researchers studied the aerodynamic damping of nonsquare cross-section buildings. Marukawa et al. [8] 


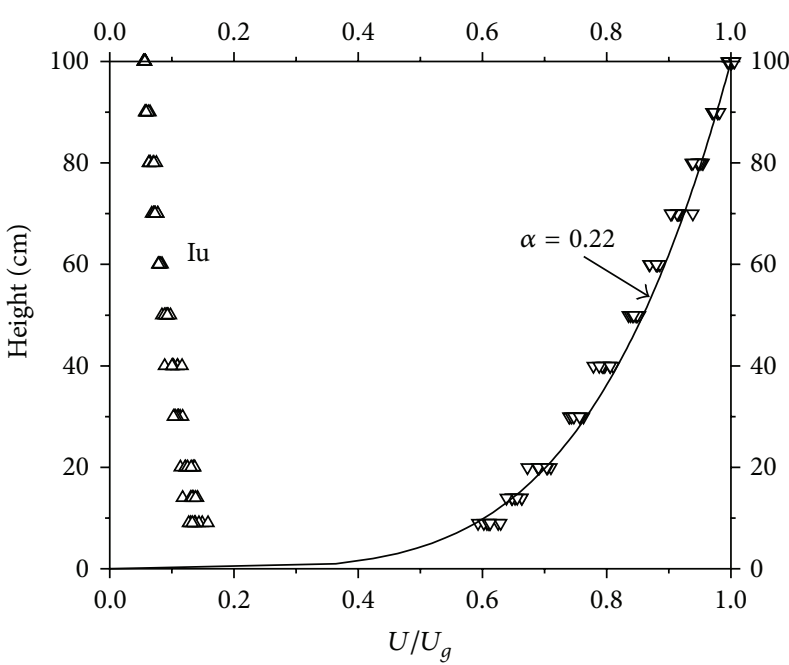

(a)

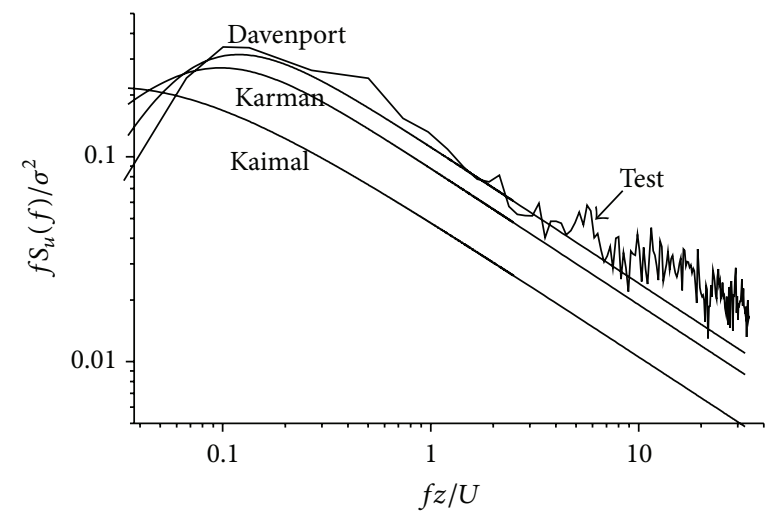

(b)

FIGURE 1: Simulated wind parameters of the suburban terrain: (a) profiles of mean wind velocity and turbulent intensity; and (b) power spectral density of fluctuating wind velocity.

investigated the aerodynamic damping characteristics of high-rise buildings with a rectangular cross-section (side ratio of 0.33 to 3 ) by using wind tunnel tests. An aeroelastic stick model and the random decrement technique (RDT) were applied to estimate the damping ratios. RDT is widely used to evaluate aerodynamic damping ratios from the random vibration responses of structures excited by random wind loads [11, 13-15], but the accuracy of this technique may not be satisfactory if data length is insufficient or if the structural modes of the models are not well-separated during vibration [16]. In the current paper, a time domain method, eigensystem realization algorithm (ERA) is used in conjunction with the RDT technique to identify the aerodynamic damping ratios. The ERA does not require excessively long data and the experiment results demonstrate that the ERA + RDT approach is efficient and can provide more precise results.

Studies on the aerodynamic damping of tall buildings are generally limited, and only discrete test results were presented. In the present research, six single-degree-offreedom (SDOF) aeroelastic models of tall buildings with typical cross-sections (square, square with concave or bevel corners, and rectangular) were tested in a wind tunnel with a suburban terrain flow field condition. The effects of wind speed, concave or bevel corner, side ratio, and wind direction on the along-wind and across-wind aerodynamic damping are studied by using the ERA + RDT method to evaluate the aerodynamic damping ratios. Several conclusions were eventually obtained.

\section{Experimental Setup}

2.1. Simulation of Wind Characteristic. The test was carried out in the TJ-1 Boundary Layer Wind Tunnel with a working section of $1.8 \mathrm{~m}$ in width and $1.8 \mathrm{~m}$ in height as well as a wind speed ranging from $3 \mathrm{~m} / \mathrm{s}$ to $32 \mathrm{~m} / \mathrm{s}$. A 1:500 scaled wind model of the natural wind flow over a suburban terrain (terrain category C based on the Chinese load code GB500092012) was simulated in the wind tunnel. The exponent of the mean wind profiles for the suburban terrain was 0.22 , and the corresponding gradient height was $450 \mathrm{~m}$. The wind characteristic was achieved by combining turbulence generating spires, a barrier at the entrance of the wind tunnel, and roughness elements along the wind tunnel floor upstream of the model. Figure 1 shows the simulated mean wind velocity profile, turbulent intensity profile, and power spectral density of the fluctuating wind velocity at the model height in the wind tunnel.

2.2. Building Models. The building models had a height of $60 \mathrm{~cm}$, which represents a height of $300 \mathrm{~m}$ for real buildings (i.e., a length scale of 1:500). The wind velocity scale of the wind tunnel test was set as $1: 8$. The other scales, such as for structural mass and frequency, were correspondingly determined based on the above basic scales $C_{V}$ and $C_{L}$. Therefore, the mass and frequency as well as time scales were $C_{m}=1.25 \times 10^{8}, C_{f}=62.5$, and $C_{t}=1 / 62.5$, respectively.

The structural parameters of the typical super highrise building should be initially determined to reasonably investigate the effects of the factors on aerodynamic damping. Firstly, in terms of investigations of a great number of tall buildings in Japan [17], the first translation mode natural frequency $\left(f_{1}\right)$ of common high-rise buildings with a height of $300 \mathrm{~m}$ is estimated to be

$$
f_{1}=\frac{1}{0.015 H} \sim \frac{1}{0.02 H}=0.167 \sim 0.222 \mathrm{~Hz}
$$

In addition, average mass densities of common highrise buildings are usually $160 \mathrm{~kg} / \mathrm{m}^{3}$ to $240 \mathrm{~kg} / \mathrm{m}^{3}$. The mass density of a typical building in this paper was set as $180 \mathrm{~kg} / \mathrm{m}^{3}$ because super high-rise buildings were prone to being light. 
TABLE 1: Dimensions of the models.

\begin{tabular}{|c|c|c|c|c|c|}
\hline \multirow{2}{*}{ Case } & \multirow{2}{*}{ Height of model (cm) } & \multirow{2}{*}{ Cross section $(\mathrm{cm})$} & \multirow{2}{*}{ Corner modified } & \multicolumn{2}{|c|}{ Frequency $(\mathrm{Hz})$} \\
\hline & & & & $f_{x}$ & $f_{y}$ \\
\hline A & 60 & $10 \times 10$ & - & 20.0 & 12.2 \\
\hline B & 60 & $10 \times 10$ & Concave corner $10 \%$ & 20.0 & 12.2 \\
\hline $\mathrm{C}$ & 60 & $10 \times 10$ & Bevel corner $10 \%$ & 20.0 & 12.2 \\
\hline $\mathrm{D}$ & 60 & $10 \times 15$ & - & 19.0 & 11.7 \\
\hline $\mathrm{E}$ & 60 & $10 \times 20$ & - & 17.8 & 11.2 \\
\hline $\mathrm{F}$ & 60 & $10 \times 30$ & - & 16.1 & 10.4 \\
\hline
\end{tabular}

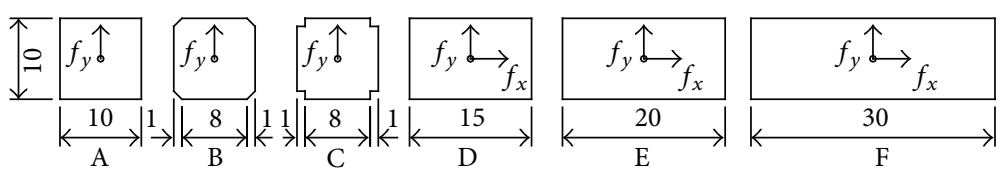

Figure 2: Cross sections of the six models (unit: $\mathrm{cm}$ ).

In this study, the parameters of the six SDOF aeroelastic models (A to F) are listed in Table 1, and the cross sections are presented in Figure 2. Six kinds of cross sections, namely, square, square with concave or bevel corners, and rectangular (side ratio $D / B$ of 0.3 to 3 ) were tested to study the aerodynamic damping of typical tall buildings.

The square prism model (Case A) is the basic one of the six models. This model had dimensions of $0.1 \mathrm{~m}(B) \times 0.1 \mathrm{~m}$ $(B) \times 0.6 \mathrm{~m}(H)$, which represents a real building with a height of $300 \mathrm{~m}$ and a breadth of $50 \mathrm{~m}$. The mass densities of the buildings $\left(\rho_{s}\right)$ were all set as $180 \mathrm{~kg} / \mathrm{m}^{3}$. The critical structural damping ratio $\left(\zeta_{s}\right)$ of the model was set as $1.2 \%$, whereas the critical structural damping ratios $\left(\zeta_{s}\right)$ of the other models were set as $1.1 \%$. The first mode frequencies for free vibrations at the $x$ and $y$ directions are shown in Table 1 .

Figure 3 shows the specially designed supporting base of the aeroelastic model, where the rigid building model could vibrate in two perpendicular directions under wind actions [11, 18, 19]. The required mass and stiffness can be achieved by selecting appropriate mass blocks and springs, respectively. Structural damping ratios can be simulated by selecting damping cards of proper size and depth for immersion into the oil pool. In the wind tunnel test, the damping cards were bent toward their vibration direction in the oil pool to ensure that the structural damping ratios are independent from their vibration amplitudes. Two miniaccelerometers were perpendicularly mounted on top of the model to measure the along-wind and across-wind responses. The testing wind velocity at the level of the model height $\left(U_{H}\right)$ ranged from $4 \mathrm{~m} / \mathrm{s}$ to $16 \mathrm{~m} / \mathrm{s}$. The data were recorded for a sampling duration of 87.38 seconds at a sampling rate of $375 \mathrm{~Hz}$; that is, 32768 data were recorded for each channel.

\section{Methods for Identifying Aerodynamic Damping}

The methods for estimating damping from a time history of random vibration responses can be classified into two categories: frequency and time domain approaches. The frequency-domain approaches are those related to spectral analysis, such as the spectra-based half-power and the spectral moment methods. The time-series approaches include the autocorrelation decay, RDT, maximum entropy estimates, autoregressive (AR), and the moving averages (ARMA).

The RDT is widely used to evaluate aerodynamic damping ratios from the random vibration responses of structures that are excited by random wind loads [11, 13-15, 20]. In the RDT method, the measured structural responses are averaged by using a common initial or triggering condition, where a random decrement function is gained and which can be considered as the free vibration responses of the structures. Structural damping ratios and frequencies can be easily acquired based on the assumption of the free vibration response.

RDT extracts free-decay responses from a series of samples but requires very long data to average. The average number of the RDT method is over 5,000 times in order to attain better results, which reveals the necessity of a large amount of data in applying the RDT technique [14]. When exponential functions are used to fit the diminishing processes of the free-decay responses, only several peak data are used to obtain the structural damping ratios and frequencies [21]. The accuracy of RDT may not be satisfactory in certain conditions, such as the nonstationary time histories of measured responses, or when the structural modes of a model are densely distributed [16].

3.1. ERA + RDT Method. The RDT is a time domain procedure and is considered in association with the time domain modal identification algorithm, such as the ERA method, to improve precision in identification. In this study, a time domain method, namely, ERA [22], is used in conjunction with the RDT technique (ERA + RDT), to evaluate the aerodynamic damping ratios based on the random vibration responses of the aeroelastic model tests. The ERA + RDT method has a higher precision than RDT and could identify the high-order mode parameters of the models with 


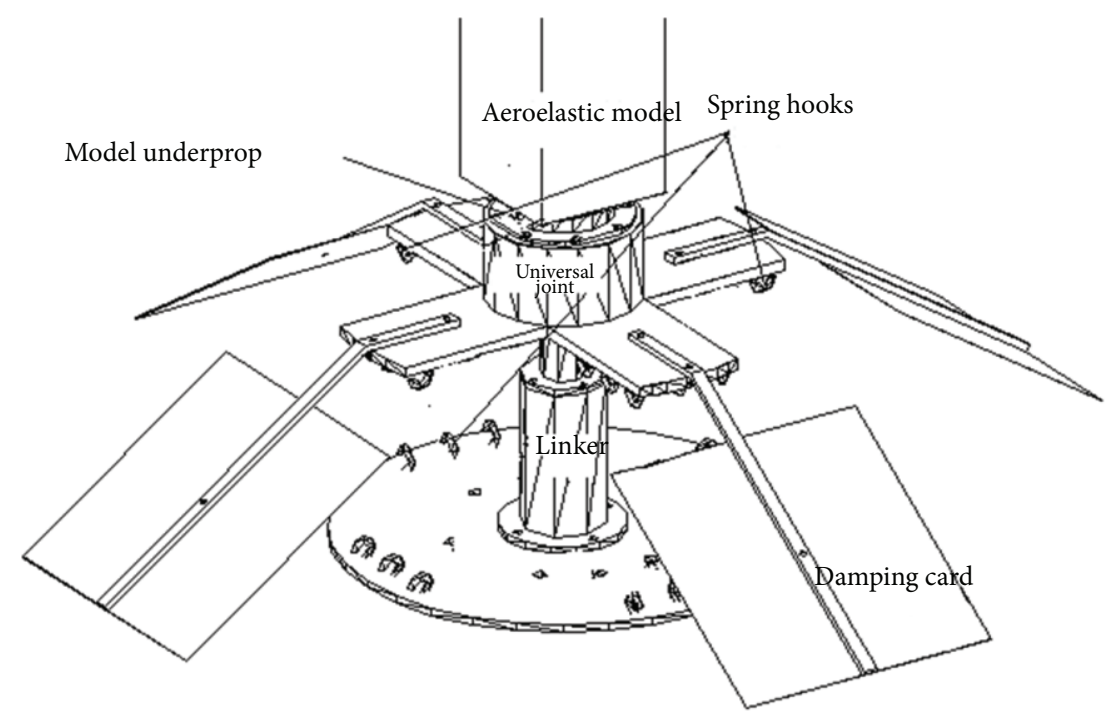

Figure 3: Base of the SDOF aeroelastic model [11].

satisfactory accuracy. The ERA + RDT method likewise does not require very long data from tests.

The ERA is based on the system impulse response or free decay response. In the discrete-time space, the motion of an $N$-degree-of-freedom system with the action of $\{u\}$ can be expressed by the state equation as follows:

$$
\begin{gathered}
\{x(k+1)\}=A\{x(k)\}+B\{u(k)\}, \\
\{y(k)\}=C\{x(k)\}
\end{gathered}
$$

where $A, B$, and $C$ are the state, input, and output matrices, respectively; $\{x(k+1)\}$ and $\{x(k)\}$ are the states at time instant $(k+1) \Delta t$ and $k \Delta t ;\{y(k)\}$ is the response at time $k \Delta t$; and $\Delta t$ is the sampling time interval.

The response $\{y(k)\}$ of the system is related to the state, input, and output matrices $A, B$, and $C$ are based on the random vibration theory:

$$
\{y(k)\}=C A^{k-1} B, \quad(k>0) .
$$

By forming the block Hankel matrix,

$$
\begin{aligned}
& H_{r s}(k-1) \\
& =\left[\begin{array}{cccc}
\{y(k)\} & \{y(k+1)\} & \cdots & \{y(k+s)\} \\
\{y(k+1)\} & \{y(k+2)\} & \cdots & \{y(k+s+1)\} \\
\vdots & \vdots & & \vdots \\
\{y(k+r)\} & \{y(k+r+1)\} & \cdots & \{y(k+s+r)\}
\end{array}\right] .
\end{aligned}
$$

The state matrix $(A)$ can be determined by using ERA:

$$
A=S^{-1 / 2} P^{T} H_{r S}(1) Q S^{-1 / 2},
$$

where $r$ and $s$ are the numbers of row and column shifts of the Hankel matrix, respectively; $P, S$, and $Q$ are the matrices used to construct the pseudoinverse of $H_{r s}(0)$, which are determined by the singular value decomposition (SVD) of the matrix $H_{r s}(0)$ :

$$
H_{r s}(0)=P S V^{T}
$$

The modal parameters of the system (building) can be determined by solving the eigenvalue problem of the state matrix $A$ and by converting the eigen pairs into a continuoustime space.

The ERA method could only identify the modal parameters of the system impulse responses or free decay responses. These are obtained by using the RDT technique, such that the random decrement functions gained by the RDT can be considered as the free vibration responses of structures.

3.2. Definition of the Aerodynamic Damping Ratio. When a building model is under the action of a random wind load in a wind tunnel, the damping ratio identified with this method includes not only the structural damping ratio, but also the aerodynamic damping ratio. The aerodynamic damping ratios can be obtained after the structural damping ratio is subtracted from the total damping ratio:

$$
\zeta_{a}=\zeta_{T}-\zeta_{s}
$$

where

$$
\begin{aligned}
& \zeta_{a} \text { is the aerodynamic damping ratio; } \\
& \zeta_{T} \text { is the total damping ratio; } \\
& \zeta_{s} \text { is the structural damping ratio of the model. }
\end{aligned}
$$

3.3. Validation of the ERA + RDT Method. The proposed method is validated through a comparison of the aerodynamic damping ratios of the square building model obtained by the ERA + RDT with short-term (87.38 s) data (current paper) and those of the same model estimated only by the RDT technique with long-term data [11]. Quan et al. [11] 


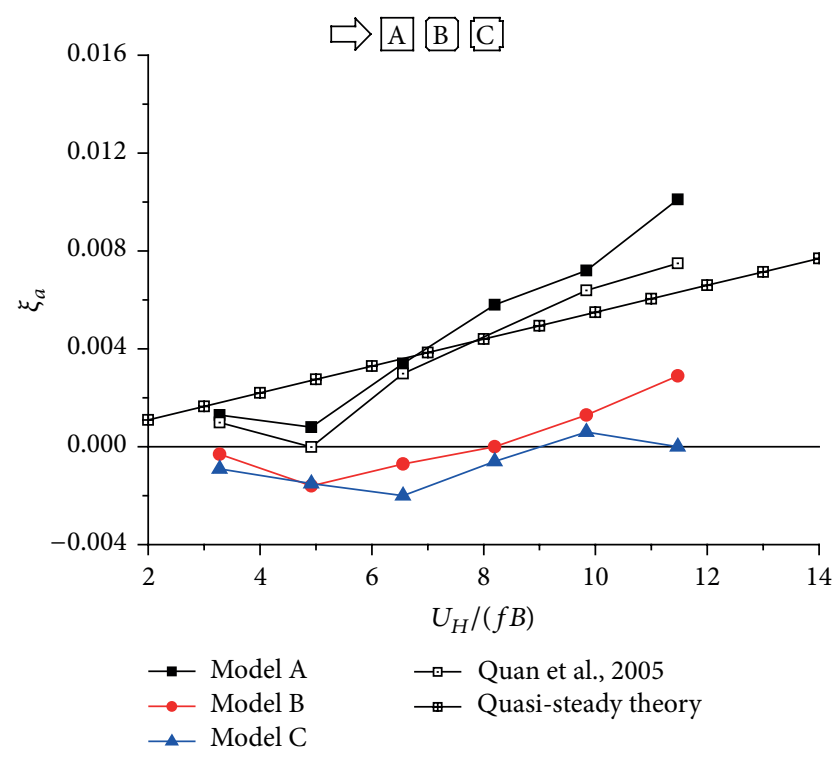

(a)

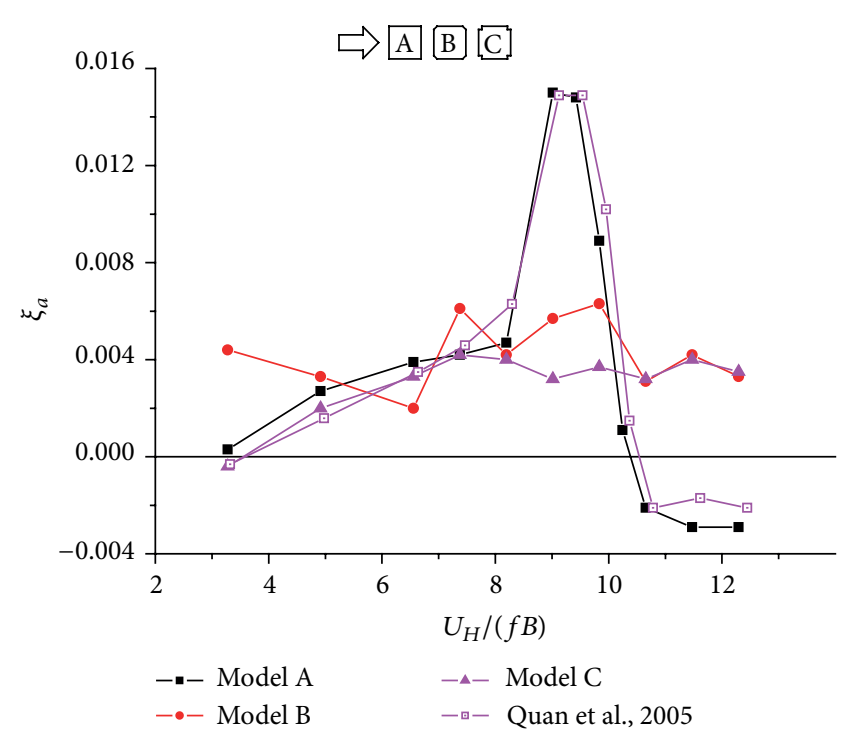

(b)

FIGURE 4: Effect of corner-modified shape: (a) along-wind; and (b) across-wind.

studied the aerodynamic damping ratios by using several structural damping ratios and terrain types. Data were recorded given a sampling duration of $825 \mathrm{~s}$ because only the RDT technique was applied. The average numbers of the random decrement function using the RDT method were 7,500 to 11,000 . Figure 4 shows the results, and the ratios identified by the ERA + RDT method were almost the same as those based on the long-term data, which indicates that the ERA + RDT method used in this paper is valid and accurate. At the same time, the identified results are compared with the calculated aerodynamic damping ratios based on the quasisteady theory [4], whose values are similar and have the same tendency.

\section{Experimental Results and Discussions}

Six kinds of cross sections of tall buildings, namely, square, square with concave or bevel corners, and rectangular (side ratio $D / B$ is 0.3 to 3 ), were tested to study the effects of wind speed, corner modifications (concave or bevel corner), side ratio, and wind direction on the aerodynamic damping of typical tall buildings. The along-wind aerodynamic damping was generally positive in most cases and gradually increased with the increase of reduced wind speed $\left(U_{r}\right)$. The acrosswind aerodynamic damping was likewise positive at low $U_{r}$ in most cases, but suddenly becomes negative when the $U_{r}$ is greater than 10.5 for the square cross-section building. Further experimentation is necessary on rectangular crosssection buildings to obtain results when the $U_{r}$ is greater than 10.

4.1. Effect of Modified Corner. Figure 4 shows the identified aerodynamic damping ratios of square buildings with and without modified corners.
4.1.1. Square Building without Modified Corners. In the alongwind direction, aerodynamic damping ratios are generally positive and increase with an increase of wind speed. In the across-wind direction, aerodynamic damping ratios are likewise positive and slowly increase with wind speed when the $U_{r}$ is

$$
U_{r}=\frac{U_{H}}{f \sqrt{B D}} \leq 8 .
$$

When $U_{r}$ steadily increases from 8 , the across-wind aerodynamic damping ratios increase rapidly and attain peak values at $U_{r}$ of approximately 9 to 10 . When wind speed further increases, the aerodynamic damping ratios suddenly decrease and become negative at $U_{r}$ greater than 10.5.

4.1.2. Square Building with Modified Corners. The aerodynamic damping ratios of corner-modified square crosssection buildings ( $10 \%$ concave corner and $10 \%$ bevel corner) tend to be similar to those of square buildings without modified corners. In the along-wind direction, aerodynamic damping ratios appear to have negative values when the $U_{r}$ is less than or equal to 7 . However, the absolute values are small and the influence of these ratios could be negligible for practical purposes. When wind speed increases, the aerodynamic damping ratios increase to positive values, which are much smaller than those of the square building. In the across-wind direction, all aerodynamic damping ratios are positive and are almost the same as those of the square building when $U_{r}$ is smaller than or equal to 8 . When $U_{r}$ is greater than 8 , the aerodynamic damping ratios of the cornermodified square buildings retain the same variation tendency as those when $U_{r}$ is less than 8 . The damping characteristics seem to indicate that the effects of the aerodynamic damping in both the along-wind and across-wind directions of the 


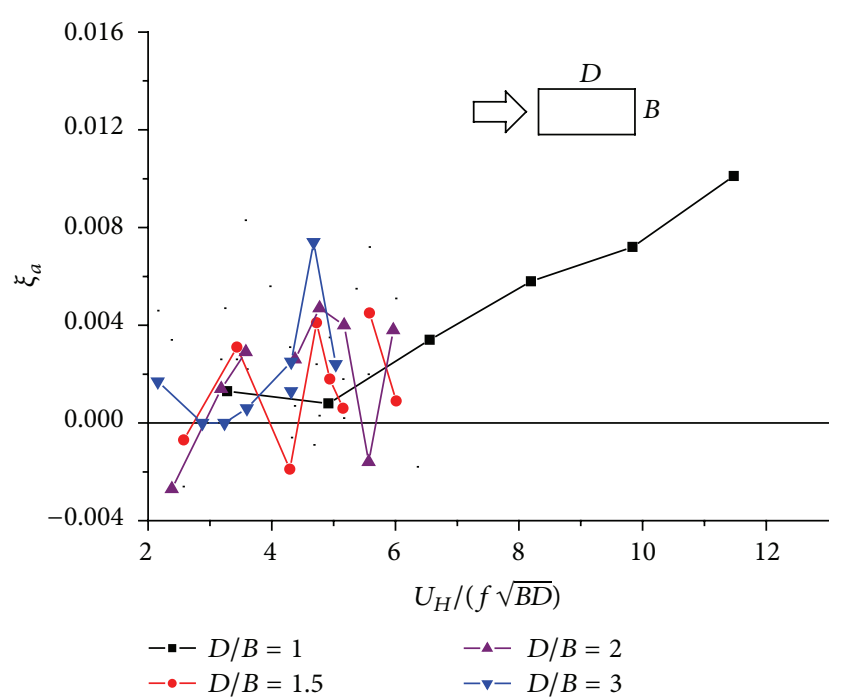

(a)

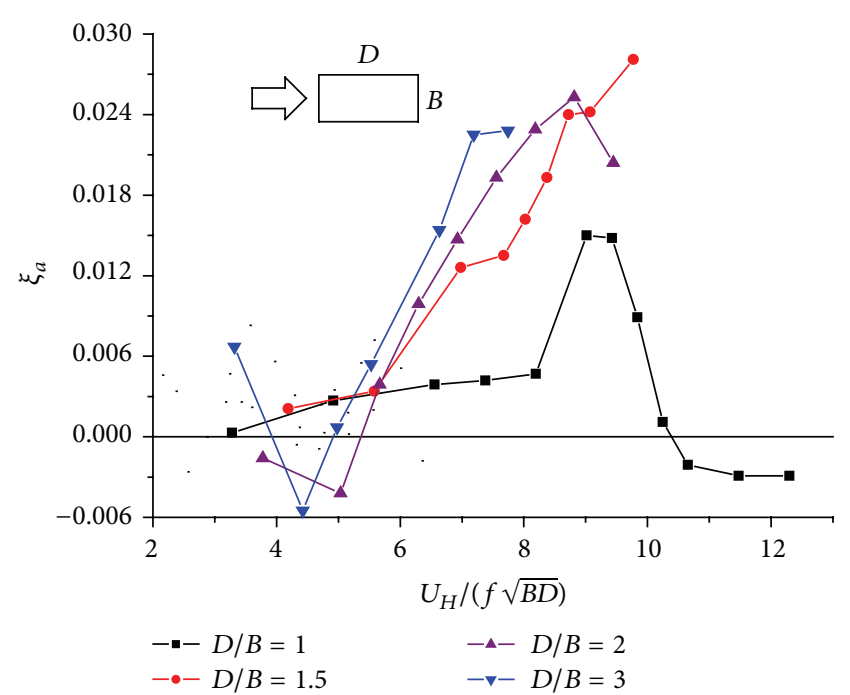

(b)

FIGURE 5: Effect of the side ratio $(D / B \geq 1)$ : (a) along-wind; and (b) across-wind.

buildings with corner modifications could be neglected for engineering purposes.

\subsection{Effect of Side Ratios (D/B)}

4.2.1. $D / B$ is Greater Than or Equal to 1. The effect of the side ratios $(D / B$ is equal to $1,1.5,2$, and 3$)$ on the aerodynamic damping of rectangular cross-section tall buildings is presented in Figure 5. In the along-wind direction, the aerodynamic damping ratios of the rectangular buildings $(D / B$ of greater than 1$)$ tend to be similar to those of the square building ( $D / B$ equal to 1$)$ when $U_{r}$ is less than or equal to 6 . When $U_{r}$ is greater than 6 , further experimentation is necessary.

In the across-wind direction, the aerodynamic damping ratios of rectangular cross-section buildings $(D / B$ equal to $1.5,2$, and 3) have a similar variation tendency with the wind speed, which increases more rapidly than those of the square building. The aerodynamic damping ratios of the rectangular buildings appear to have negative values when the $U_{r}$ is less than or equal to 5 , with a minimum value of $-0.55 \%$. The further increase of reduced wind velocity from 6 causes the aerodynamic damping ratios of rectangular buildings to generally increase with a side ratio. All the aerodynamic damping ratios are much larger than those of the square building.

The across-wind aerodynamic damping ratios of the square building suddenly decrease and become negative values when $U_{r}$ is greater than 10.5. Further experimentation is necessary to obtain results for rectangular cross-section buildings with $U_{r}$ greater than 10 .

4.2.2. D/B Is Smaller Than or Equal to 1. Figure 6 shows the effect of the side ratios $(D / B$ equal to $1,0.67,0.5$, and 0.33$)$ on the aerodynamic damping of rectangular cross-section tall buildings. In the along-wind direction, the aerodynamic damping ratios of the four kinds of side ratios are positive. The aerodynamic damping ratios of rectangular buildings generally decrease with the side ratio but are larger than those of the square building.

In the across-wind direction, the aerodynamic damping ratios of buildings with a $D / B$ equal to 0.67 have a similar variation tendency as those of the square building when the $U_{r}$ is less than or equal to 6 . The aerodynamic damping ratios of buildings with $D / B$ s equal to 0.5 and 0.33 are small, and finding the variation laws with the wind speed is difficult. The aerodynamic damping ratios of rectangular buildings with $D / B$ s equal to 1 also appeared to have some negative values, but the absolute values were very small. Further experimentation is necessary for $U_{r}$ that is greater than 6 .

4.2.3. Comparison between the Present Study and Marukawa. Marukawa et al. [8] identified the along-wind and acrosswind aerodynamic damping ratios of square and rectangular cross-section buildings by using the RDT from a SDOF aeroelastic model wind tunnel test. The side ratios of the models ranged from 0.33 to 3 with a basic aspect ratio of 6 . The simulated wind flow was the flow over the open terrain, where the exponent of the wind profile and the turbulent intensity at the top of the model were 0.167 and $10.7 \%$, respectively. The structural damping ratio of the building model was $1 \%$.

The comparisons of the aerodynamic damping ratios between the present study and Marukawa are shown in Figure 7. The aerodynamic damping ratios of the two studies revealed a common tendency, despite the differences in the values of the aerodynamic damping ratios that may have been caused by the different simulated terrain conditions.

4.3. Effect of Wind Direction. Studying the effect of wind direction on aerodynamic damping is important for practical purposes because wind flow is not always normal to the building facades. The variations of the aerodynamic damping 


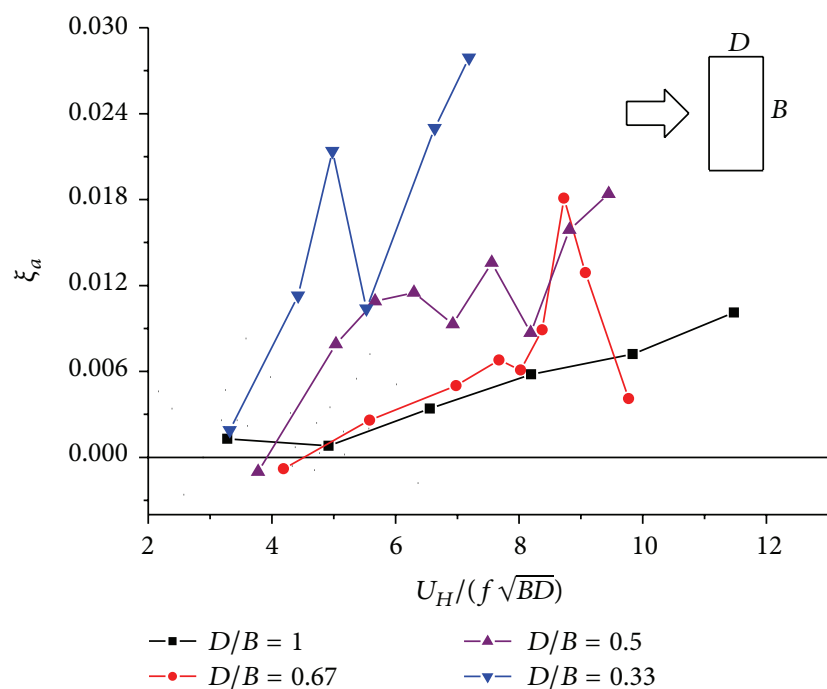

(a)

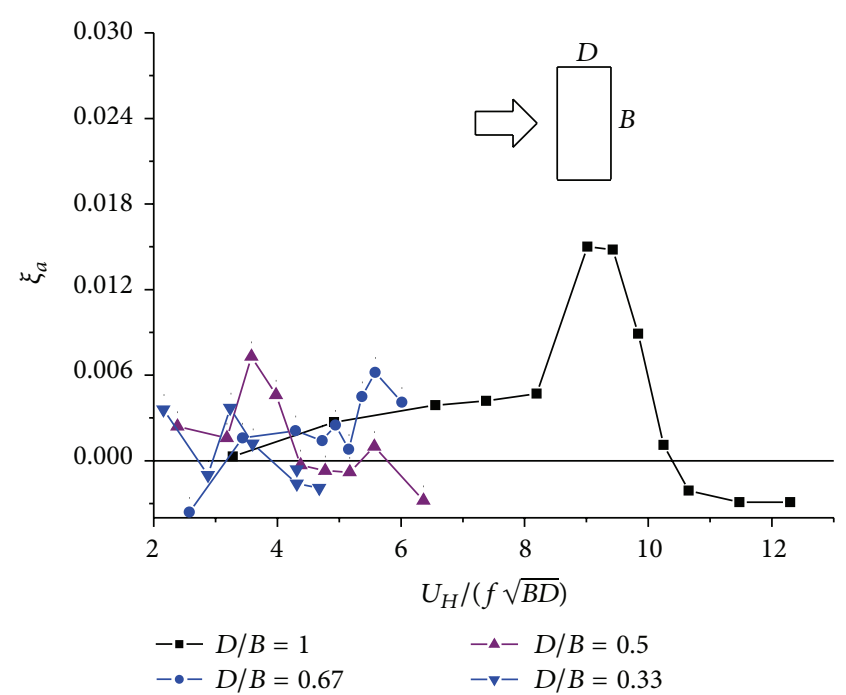

(b)

FIGURE 6: Effect of the side ratio $(D / B \leq 1)$ : (a) along-wind; and (b) across-wind.

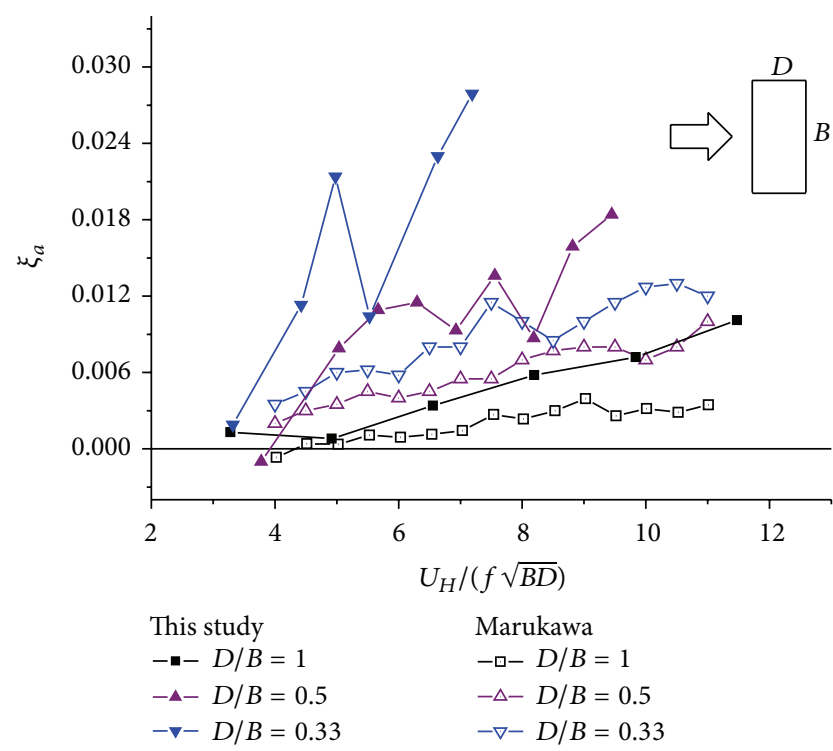

(a)

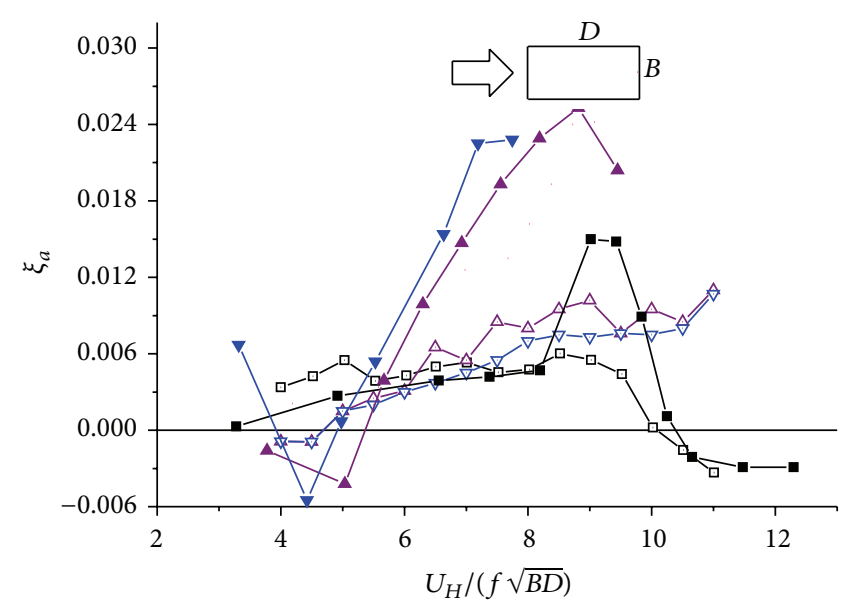

$$
\begin{aligned}
& \text { This study } \\
& --D / B=1 \\
& -\mathbf{-}-D / B=2 \\
& -\nabla-D / B=3
\end{aligned}
$$

(b)

Figure 7: Comparison between the present study and that of Marukawa et al. [8]: (a) along-wind $(D / B \leq 1)$; and (b) across-wind ( $D / B \geq 1)$.

ratios of the rectangular cross-section buildings ( $D / B$ s of 1.5 and 3) with the wind direction are illustrated in Figure 8.

The aerodynamic damping ratio for the rectangular building with a $D / B$ of 1.5 tends to increase with the increase of wind angle. The minimum value was $-0.55 \%$ at a $0^{\circ}$ angle (i.e., across-wind direction) and $U_{r}$ of 4.4. The maximum value was $3.0 \%$ at an $80^{\circ}$ angle and $U_{r}$ of 6.6 .

The aerodynamic damping ratios for the building with a $D / B$ of 3 were all positive with the maximum value of $2.9 \%$ at a $0^{\circ}$ angle (across-wind direction) and $U_{r}$ of 9.8. The aerodynamic damping ratios of the two rectangular buildings likewise have the common tendency to roughly increase with the increase of wind speed.

\section{Concluding Remarks}

The conclusions on the along-wind and across-wind aerodynamic damping ratios of different cross-sections of tall buildings as obtained by using the wind tunnel experiment are as follows.

(1) The aerodynamic damping ratios identified by the ERA + RDT method were almost the same as those based on the long-term data, which indicates that the ERA + RDT method used in this paper is valid and accurate.

(2) The along-wind aerodynamic damping is positive in most cases and gradually increases with the increase 


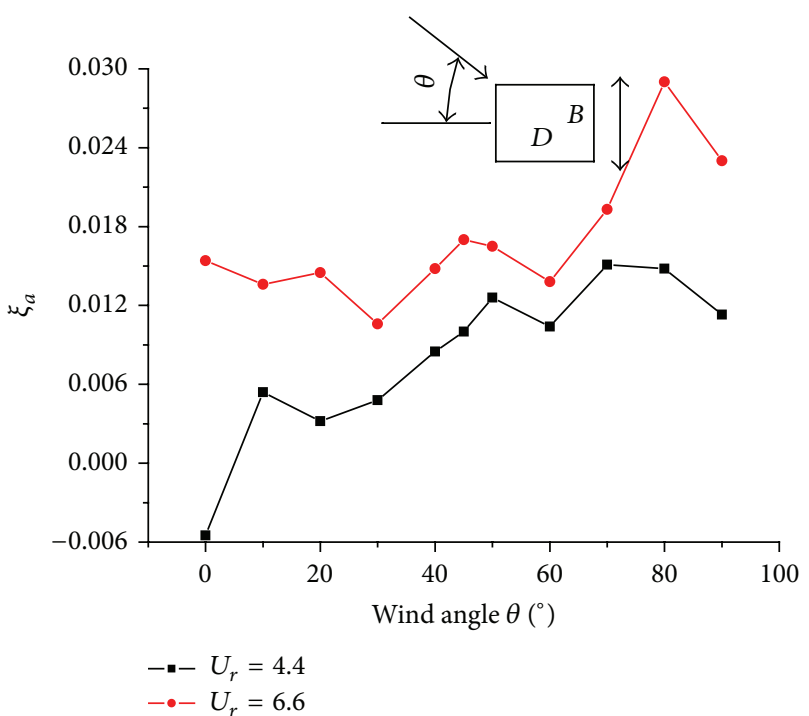

(a)

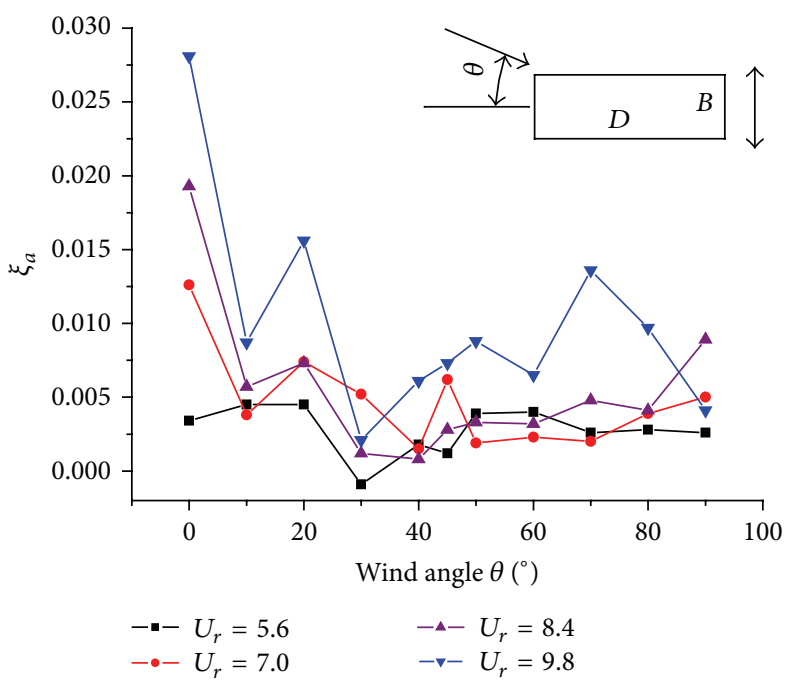

(b)

FIGURE 8: Variations of the aerodynamic damping ratios with the wind angle: (a) $D / B=1.5$; and (b) $D / B=3$.

of $U_{r}$. The across-wind aerodynamic damping was likewise positive at low $U_{r}$ in most cases, but suddenly became negative when the $U_{r}$ is greater than 10.5 for the square cross-section building. Further experimentation on rectangular cross-section buildings is necessary to obtain results when $U_{r}$ is greater than 10 .

(3) The along-wind aerodynamic damping ratios for tall buildings with a corner-modified square crosssection (10\% concave corner and $10 \%$ bevel corner), appeared to have some negative and small absolute values at a low wind speed. The across-wind aerodynamic damping ratios were all positive and small. These results indicate that the effects of aerodynamic damping in the along-wind and across-wind directions of buildings with corner modifications may be neglected for engineering purposes.

(4) Both the along-wind and across-wind aerodynamic damping ratios for the rectangular cross-section buildings with a $D / B$ greater than 1 appeared to have some negative values at a low wind speed. The acrosswind aerodynamic damping ratios at a high wind speed were large, reaching $2.9 \%$.

(5) All of the along-wind aerodynamic damping ratios for the rectangular cross-section buildings with a $D / B$ smaller than 1 were positive, and the across-wind aerodynamic damping ratios appeared to have some negative values at a low wind speed. The across-wind aerodynamic damping ratios at a high wind speed were large, reaching $2.3 \%$ to $2.8 \%$.

\section{Acknowledgment}

This project is supported by Chinese National Natural Science Foundation (nos. 51178352, 90715040, and 91215302), which is gratefully appreciated.

\section{References}

[1] A. G. Davenport, The Influence of Turbulence on the Aeroelastic Responses of Tall Structures to Wind, University of Karlsruhe, Karlsruhe, Germany, 1979.

[2] J. D. Holmes, "Along-wind response of lattice towers-II. Aerodynamic damping and deflections," Engineering Structures, vol. 18, no. 7, pp. 483-488, 1996.

[3] J. D. Holmes, Wind Loading of Structures, E \& FN Spon, London, UK, 2001.

[4] R. D. Gabbai and E. Simiu, "Aerodynamic damping in the along-wind response of tall buildings," Journal of Structural Engineering, vol. 136, no. 1, pp. 117-119, 2010.

[5] A. Kareem, Wind excited motion of buildings [Ph.D. thesis], Colorado State University at Fort Collin, Colorado, Colo, USA, 1978.

[6] A. Steckley, Motion-induced wind forces on chimneys and tall buildings [Ph.D. thesis], University of Western Ontario, Ontario, Canada, 1989.

[7] H. Nishimura and Y. Taniike, "Unsteady wind force on a square prism in a turbulent boundary layer," in Proceedings of the 9th International Conference on Wind Engineering: Retrospect and Prospect (ICWE '95), pp. 195-203, New Delhi, India, 1995.

[8] H. Marukawa, N. Kato, K. Fujii, and Y. Tamura, "Experimental evaluation of aerodynamic damping of tall buildings," Journal of Wind Engineering and Industrial Aerodynamics, vol. 59, no. 2-3, pp. 177-190, 1996.

[9] Y. Watanabe, N. Isyumov, and A. G. Davenport, "Empirical aerodynamic damping function for tall buildings," Journal of Wind Engineering and Industrial Aerodynamics, vol. 72, no. 13, pp. 313-321, 1997.

[10] C. M. Cheng and Y. C. Chiang, "Acrosswind aerodynamic damping of rectangular tall buildings," in Proceedings of the 2nd International Symposium on Wind and Structures, Busan, Republic of Korea, 2002.

[11] Y. Quan, M. Gu, and Y. Tamura, "Experimental evaluation of aerodynamic damping of square super high-rise buildings," Wind and Structures, vol. 8, no. 5, pp. 309-324, 2005. 
[12] H. Hayashida, Y. Mataki, and Y. Iwasa, "Aerodynamic damping effects of tall building for a vortex induced vibration," Journal of Wind Engineering and Industrial Aerodynamics, vol. 43, no. 1-3, pp. 1973-1983, 1992.

[13] S. R. Ibrahim, "Random decrement technique for modal identification of structures," Journal of Spacecraft and Rockets, vol. 14, no. 11, pp. 696-700, 1977.

[14] Y. Tamura and S. Suganuma, "Evaluation of amplitudedependent damping and natural frequency of buildings during strong winds," Journal of Wind Engineering and Industrial Aerodynamics, vol. 59, no. 2-3, pp. 115-130, 1996.

[15] A. Kareem and K. Gurley, "Damping in structures: its evaluation and treatment of uncertainty," Journal of Wind Engineering and Industrial Aerodynamics, vol. 59, no. 2-3, pp. 131-157, 1996.

[16] A. P. Jeary, "Damping in tall buildings-a mechanism and predictor," Earthquake Engineering and Structural Dynamics, vol. 14, no. 5, pp. 733-759, 1986.

[17] Y. Tamura, K. Suda, and A. Sasaki, "Damping in buildings for wind resistant design," in Proceedings of the International Symposium on Wind and Structures for the 21st Century, pp. 115129, Cheju, Republic of Korea, January 2000.

[18] T. H. Yi, H. N. Li, and X. D. Zhang, "Sensor placement on Canton Tower for health monitoring using asynchronous-climb monkey algorithm," Smart Materials and Structures, vol. 21, no. 12, Article ID 125023, pp. 1-12, 2012.

[19] T. H. Yi, H. N. Li, and X. Wang, "Multi-dimensional sensor placement optimization for Canton Tower focusing on application demands," Smart Structures And Systems, vol. 12, no. 3-4, pp. 235-250, 2013.

[20] H. F. Bai, T. H. Yi, H. N. Li, and L. Ren, "Multisensors on-site monitoring and characteristic analysis of UHV transmission tower," International Journal of Distributed Sensor Networks, vol. 2012, Article ID 545148, 10 pages, 2012.

[21] R. W. Clough and J. Penzien, Dynamics of Structures, Computers \& Structures, Berkeley, Calif, USA, 3rd edition, 2003.

[22] J. Juang and R. S. Pappa, "An Eigensystem Realization Algorithm for modal parameter identification and model reduction," Journal of Guidance, Control, and Dynamics, vol. 8, no. 5, pp. 620-627, 1985. 


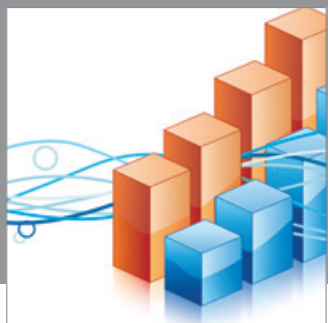

Advances in

Operations Research

mansans

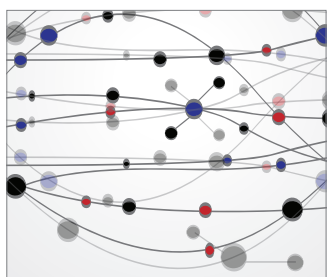

The Scientific World Journal
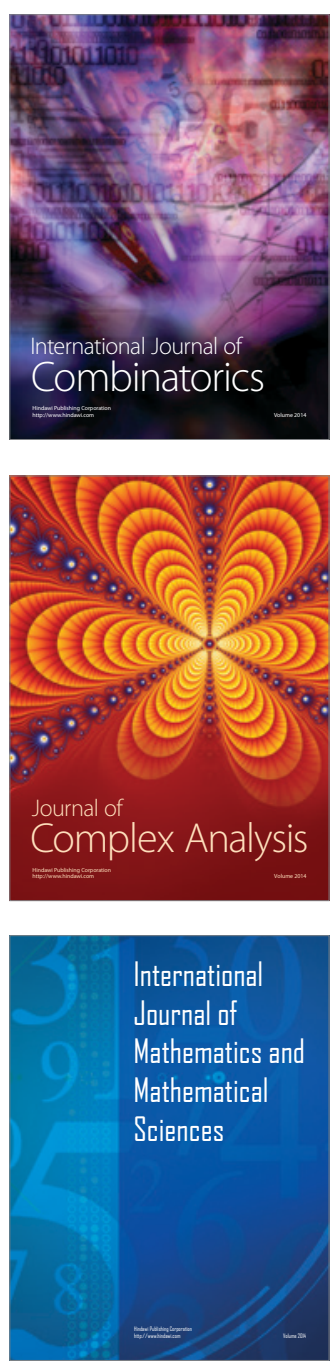
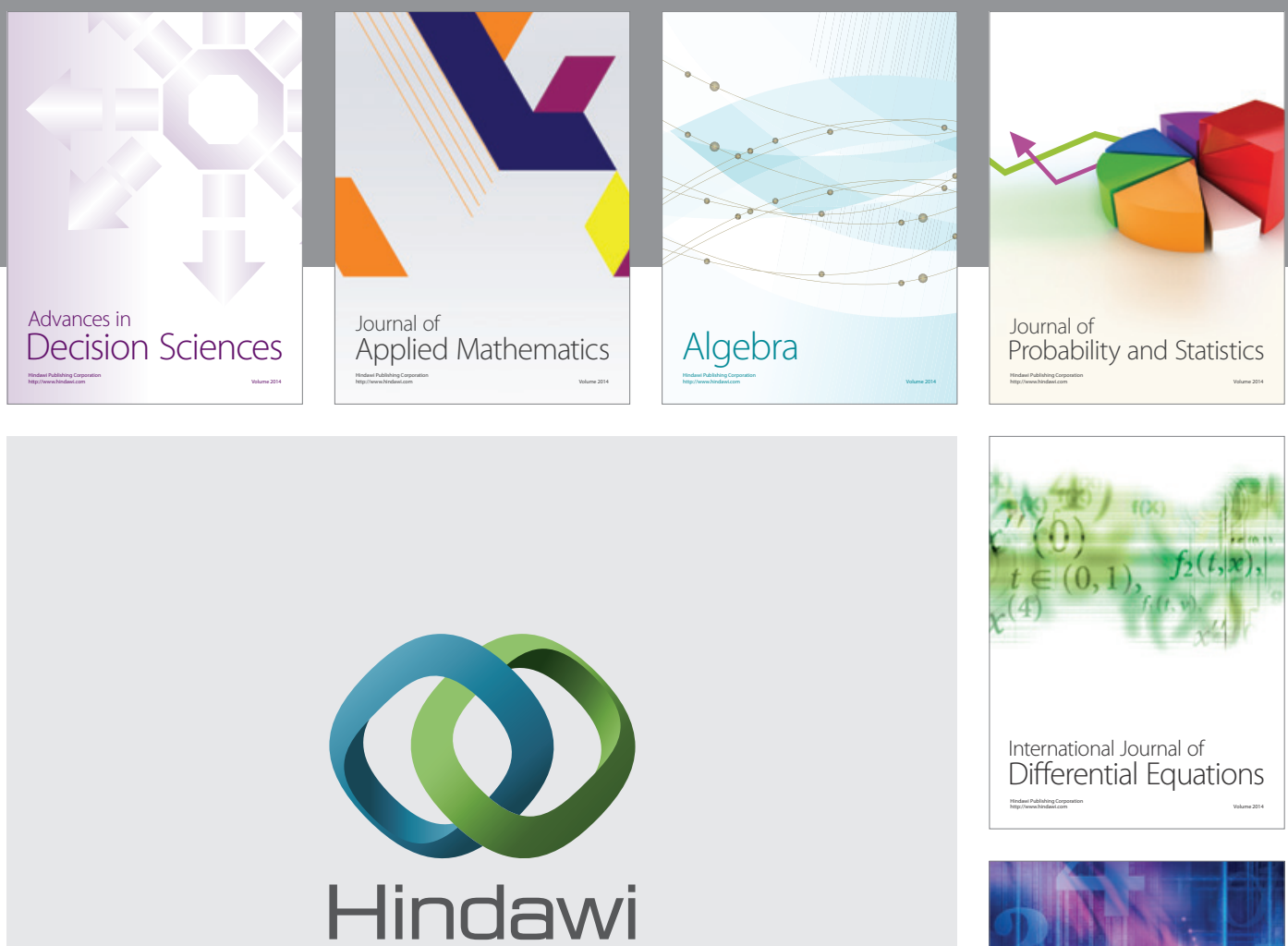

Submit your manuscripts at http://www.hindawi.com
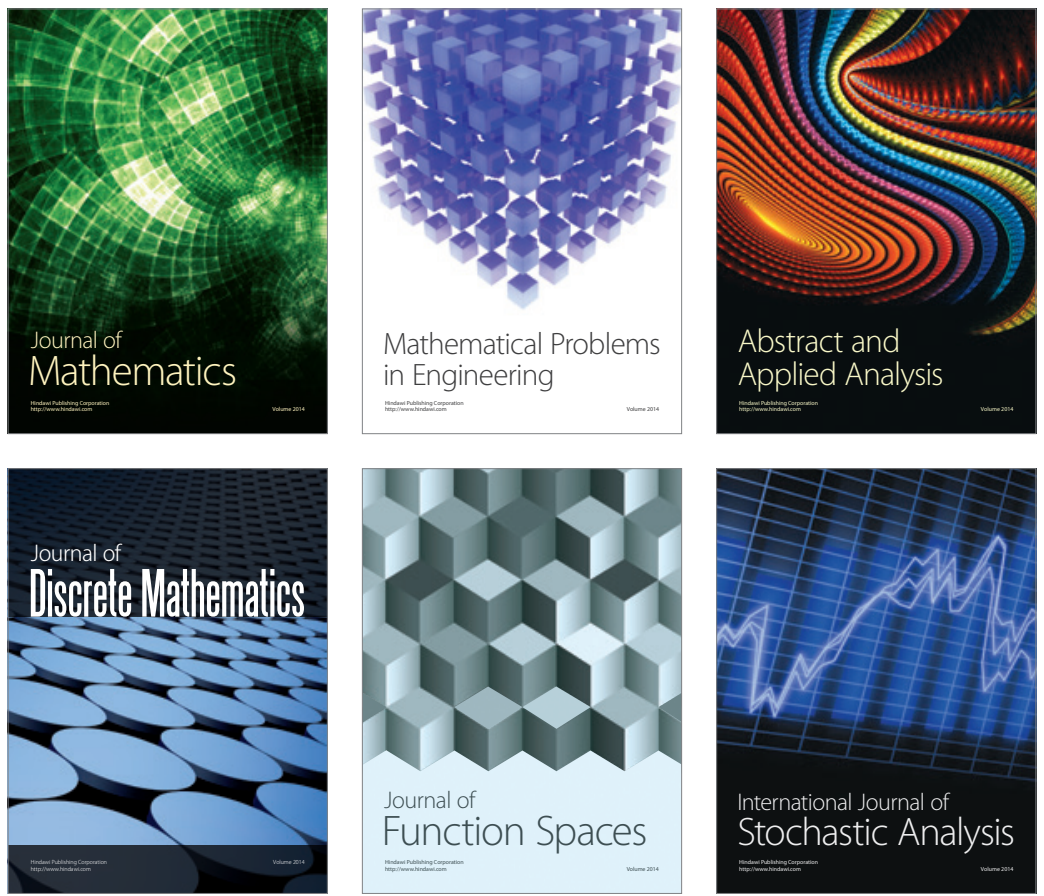

Journal of

Function Spaces

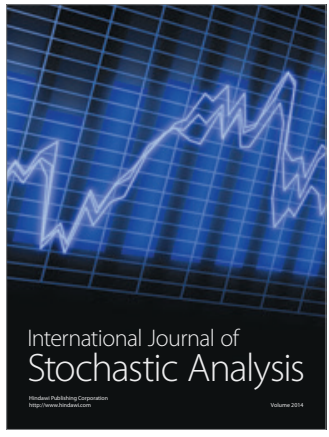

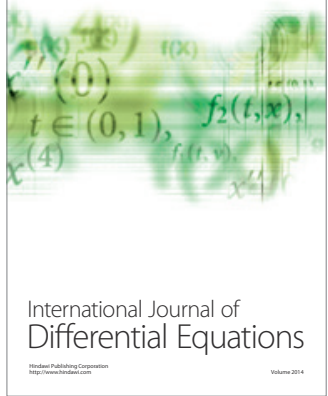
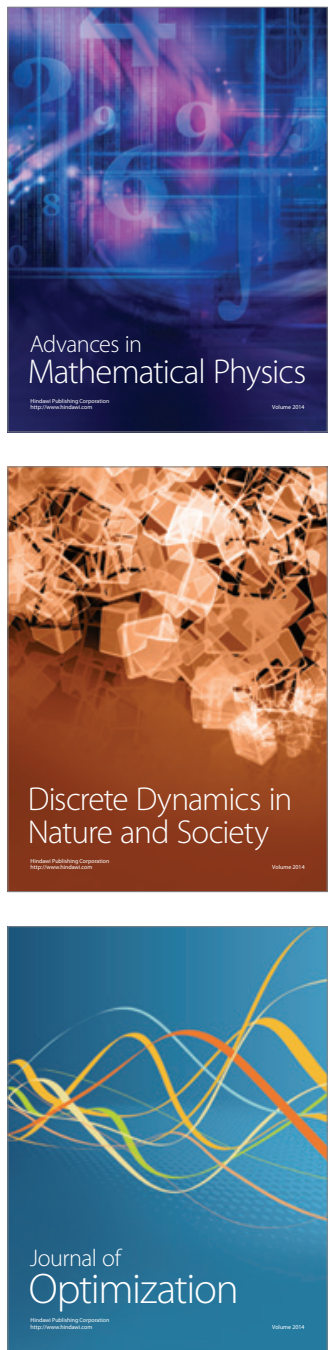